\title{
A Dispersive Inelastic X-ray Scattering Spectrometer for Use at X-ray Free Electron Lasers
}

\author{
Jakub Szlachetko ${ }^{1,2, *}$, Maarten Nachtegaal ${ }^{1}$, Daniel Grolimund ${ }^{1}$, Gregor Knopp ${ }^{1}$, \\ Sergey Peredkov ${ }^{3}$, Joanna Czapla-Masztafiak ${ }^{4}$ and Christopher J. Milne ${ }^{1, *}$ \\ 1 Paul Scherrer Institut, 5232 Villigen, Switzerland; maarten.nachtegaal@psi.ch (M.N.); \\ daniel.grolimund@psi.ch (D.G.); gregor.knopp@psi.ch (G.K.) \\ 2 Institute of Physics, Jan Kochanowski University, 25-001 Kielce, Poland \\ 3 Max-Planck-Institute for Chemical Energy Conversion, 45470 Mülheim an der Ruhr, Germany; \\ sergey.peredkov@cec.mpg.de \\ 4 The Henryk Niewodniczanski Institute of Nuclear Physics, Polish Academy of Sciences, 31342 Kraków, \\ Poland; joanna.czapla@ifj.edu.pl \\ * Correspondence: jakub.szlachetko@ujk.edu.pl (J.S.); chris.milne@psi.ch (C.J.M.); Tel.: +48-41-349-6440 (J.S.); \\ +41-56-310-5477 (C.J.M.)
}

Academic Editor: Kiyoshi Ueda

Received: 14 July 2017; Accepted: 26 August 2017; Published: 1 September 2017

\begin{abstract}
We report on the application of a short working distance von Hamos geometry spectrometer to measure the inelastic X-ray scattering (IXS) signals from solids and liquids. In contrast to typical IXS instruments where the spectrometer geometry is fixed and the incoming beam energy is scanned, the von Hamos geometry allows measurements to be made using a fixed optical arrangement with no moving parts. Thanks to the shot-to-shot capability of the spectrometer setup, we anticipate its application for the IXS technique at X-ray free electron lasers (XFELs). We discuss the capability of the spectrometer setup for IXS studies in terms of efficiency and required total incident photon flux for a given signal-to-noise ratio. The ultimate energy resolution of the spectrometer, which is a key parameter for IXS studies, was measured to the level of $150 \mathrm{meV}$ at short crystal radius thanks to the application of segmented crystals for X-ray diffraction. The short working distance is a key parameter for spectrometer efficiency that is necessary to measure weak IXS signals.
\end{abstract}

Keywords: dispersive X-ray spectrometer; von Hamos geometry; inelastic X-ray scattering; $\mathrm{X}$-ray free electron laser; SwissFEL; segmented crystal

\section{Introduction}

With the continuous increase in X-ray flux available from accelerator and lab-based sources, many demanding techniques are now being explored and applied in a variety of research fields. One class of techniques that has recently received significant attention has been the application of dispersive $\mathrm{X}$-ray spectrometer geometries to measure inelastic X-ray scattering signals from a wide-range of samples. Dispersive $X$-ray spectrometry consists of using a crystal to simultaneously energy-resolve a broad spectral range of the X-rays scattered or emitted from the sample after exposure to an X-ray source. This experimental description covers everything from non-resonant and resonant $X$-ray emission spectroscopy (XES [1] and RXES [2], respectively) to X-ray Raman scattering (XRS) [3,4]. In general, these dispersive spectrometers cover a finite range of $X$-ray bandwidth in a fixed geometry. This allows them to measure a range of the scattered X-ray spectrum in a single measurement, avoiding the necessity of scanning any part of the spectrometer or the incident beam energy. Here, we will describe the characterization and application of such a spectrometer based on the von Hamos geometry using segmented cylindrically bent crystals with $25 \mathrm{~cm}$ radius of curvature. This spectrometer is an 
evolution of our previous design [5], which has been in operation at the SuperXAS beamline at the Swiss Light Source (Paul Scherrer Institute, Switzerland) since 2012, as well as being used in temporary installations [6-9] at the Advanced Photon Source [10] (Argonne National Labs, Lemont, IL, USA), the SACLA XFEL [11] (Spring-8, Hyogo Prefecture, Japan), and the LCLS XFEL [12] (SLAC National Accelerator Laboratory, Menlo Park, CA, USA). Similar spectrometers will also be available at Experimental Station Alvra [13] at the SwissFEL XFEL [14] when it begins user operation in 2018.

The inelastic X-ray scattering technique (IXS), also called X-ray Raman scattering (XRS), is based on a photon-in photon-out scattering process of hard X-rays from low Z elements [4,15-18]. Through this scattering process, the core electron is excited to an unoccupied electronic state just above the Fermi level, and the energy loss shifts the scattered photon energy to lower values. The energy conservation for the IXS process is expressed by $E_{1}=E_{\text {initial }}+E_{\text {electron }}+E_{2}$, where $E_{1}$ and $E_{2}$ are the energies of incoming and scattered X-rays, respectively. The sum of $E_{\text {initial }}$ and $E_{\text {electron }}$ represent the total energy loss of the scattered X-ray, where $E_{\text {initial }}$ stands for the binding energy of an electron and $E_{\text {electron }}$ represents its energy above the Fermi level. By changing the energy of either $E_{1}$ or $E_{2}$, and monitoring $E_{1}$ and $E_{2}$ energies, the unoccupied electronic states probed by the scattering electron may thus be determined.

Compared to soft X-ray absorption spectroscopy (XAS) measurements $(<1 \mathrm{keV})$, which are typically employed for electronic state and structure determination in low Z elements, the IXS technique has both advantages and limitations. The primary drawback of applying the IXS technique is the low cross section for the scattering process. As compared to resonant X-ray scattering, the IXS yields are lower by $10^{-4}-10^{-6}$. On the other hand, the IXS technique provides capabilities that are complementary when compared to soft-XAS techniques. The IXS technique uses hard X-rays for incoming and emitted $\mathrm{X}$-ray energies; therefore, the penetration depth is much larger, making the IXS technique bulk-sensitive. Thanks to this advantage, the IXS technique may thus be applied to probe the electronic structure of low Z elements in liquids, concentrated heterogeneous materials, or matter under in situ conditions. To date, the IXS technique has been applied in many scientific areas where soft $X$-ray techniques could either not be applied $[19,20]$ or could not probe the desired state of matter $[21,22]$.

The IXS technique is generally implemented at synchrotron sources at dedicated beamlines, equipped with instruments ensuring good energy resolution and efficient $X$-ray detection [3,23-25]. In order to obtain good quality spectra with relatively short acquisition times, the IXS signal is often recorded by scanning the incident X-ray energy rather than scanning the emission spectrometer. Such an approach, called inverse-IXS, allows the efficiency of the IXS experiments to be improved by building X-ray spectrometers equipped with multiple analyzer crystals. Such spectrometers, arranged in the Johann geometry, are operated at a fixed Bragg angle close to 90 degrees. A large solid angle can be achieved by using even a few tens of analyzer crystals. To date, this experimental approach is the best possible approach for use at 3rd-generation storage rings, which are characterized by very stable beam parameters and allow for fast, reproducible scanning of the incident $X$-ray beam energy using fixed-exit double-crystal monochromators synchronized to insertion device gaps. This approach cannot be applied at XFELs, where the pulse and photon energy stability are poor and vary significantly from pulse to pulse [26,27]. This means the application of the IXS technique at an XFEL should avoid, if possible, the necessity of scanning the incident photon energy. An alternative approach to scanning the incident $X$-ray photon energy is to use a dispersive $X$-ray spectrometer at a fixed incident $X$-ray beam energy. This allows the full and direct IXS spectrum to be obtained in a single acquisition, and each acquisition can then be simply summed up, removing the necessity of both signal normalization and changing the incident beam photon energy. This approach is clearly advantageous for sources where the stability of the incident $X$-ray beam parameters varies from pulse to pulse.

Due to the properties of X-ray radiation delivered by XFEL sources, the implementation of $\mathrm{X}$-ray spectroscopy techniques commonly applied and established at synchrotron sources is not straightforward due to the inherent instabilities of the XFEL beam. In the present work, we report on the application of a dispersive von Hamos spectrometer to measure the IXS signals from solid 
and liquid samples. Thanks to the dispersive detection, the entire IXS signal may be measured on a shot-to-shot basis. Moreover, the shape of the IXS signal does not depend on the incident beam energy, and only requires shifting the IXS spectra according to the energy conservation rule to be centered on the spectrometer acquisition bandwidth. Therefore, combining a dispersive-type spectrometer with the self-seeded operation of an XFEL source $[26,28]$ will allow one to record IXS signals for every X-ray pulse, improving the efficiency of the experiment.

\section{Materials and Methods}

The experiments were performed at the SuperXAS and microXAS beamlines of the Swiss Light Source (Paul Scherrer Institute, Villigen, Switzerland). We employed the von Hamos spectrometer described in detail in [5], thus only the general characteristics and operational details specific to its application to inelastic $X$-ray scattering studies will be presented here.

The schematic drawing of the von Hamos geometry employing segmented crystals is presented in Figure 1. The von Hamos setup consists of three main components: the X-ray source located at the sample position, the analyzer crystal and a position-sensitive detector. The crystal and sample/detector axes are separated at a distance equal to the radius of curvature $(R)$ of the analyzer crystal, and the detector axis is positioned along the interaction point of the incoming X-rays on the sample (see Figure 1). The X-rays scattered from the sample will undergo a diffraction process from the crystal if the Bragg law criteria is met. In the von Hamos geometry, the Bragg angle is defined by the X-ray direction with respect to the crystal position (along crystal axis $C R Y_{P O S}$ ) and is described by the following formula:

$$
\theta_{B}=\tan ^{-1}\left(\frac{R}{C R Y_{P O S}}\right)
$$
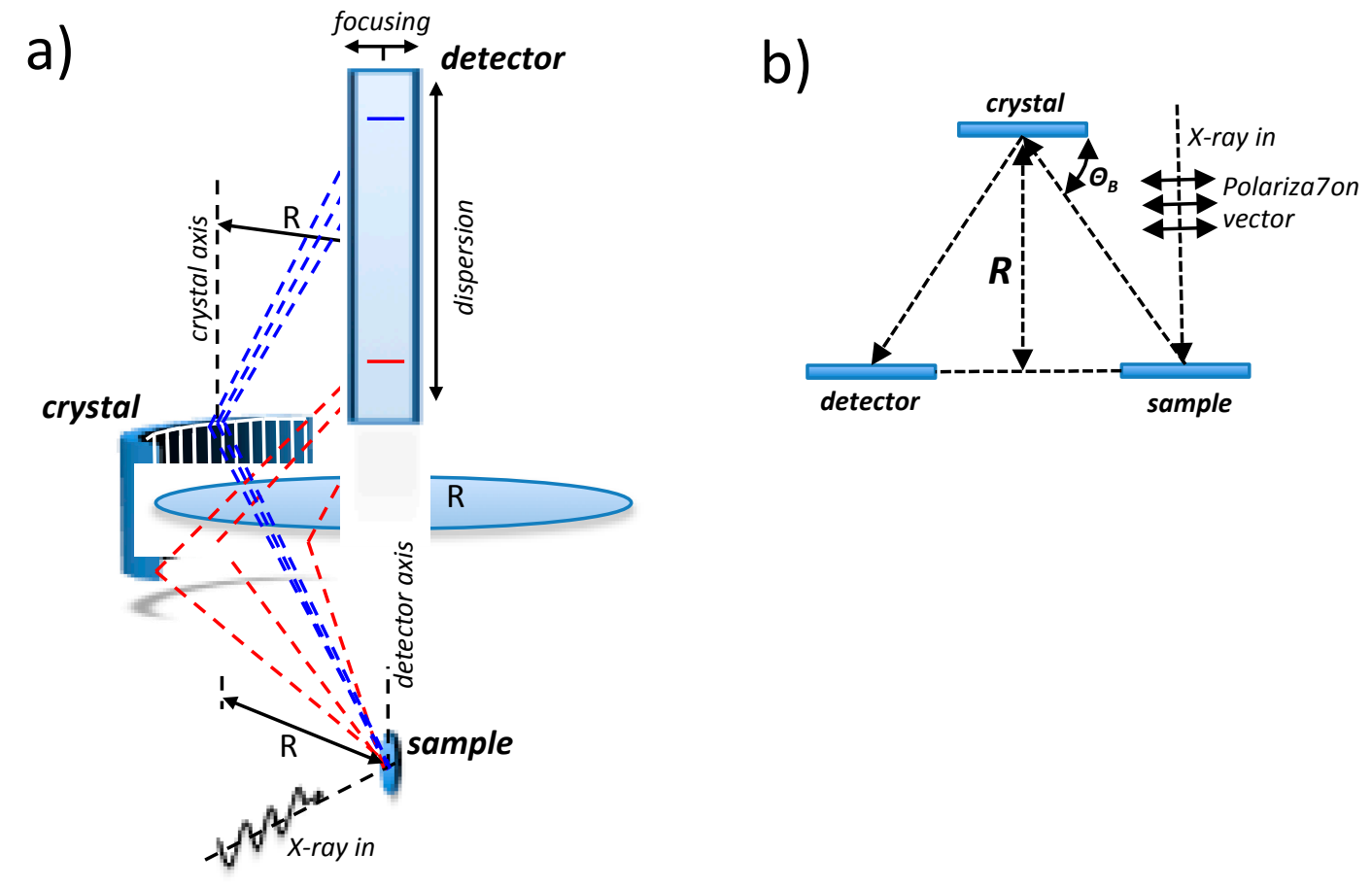

Figure 1. (a) Schematic of the von Hamos spectrometer layout employing segmented crystals for X-ray diffraction in a vertical scattering geometry; (b) Schematic view of the spectrometer geometry along the dispersive axis as applied to inelastic X-ray scattering (IXS) studies.

The formula implies that the Bragg angle range, and hence the energy range, covered by the spectrometer is limited only by the length, along the dispersive axis, of the crystal or detector. In the 
typical von Hamos geometry, the crystal is continuously bent in the focusing plane in order to direct the diffracted X-rays onto a single spot on the detector. In the present setup, we used a segmented crystal design that allows one to maintain the energy resolution at the level of the Darwin width of the reflection provided by a perfect, flat crystal. Indeed, crystal segmentation does not introduce strain in the crystal when the crystal segments are attached to the curved crystal support. The strain induced by the crystal curvature is the major source of the poor energy resolution obtained using bent crystals. The application of a segmented crystal leads to similar quasi-focusing properties of the von Hamos setup as when bent crystals are used. As schematically shown in Figure 1 by the blue dashed line, after diffraction on one crystal segment, the X-rays will focus onto the detector plane. This focus will have a size equal to two times the size of the crystal segment. Since all the segments are placed on a common radius, the total spot size on the detector will be the same, independently of the number of segments used (Figure 1, red dashed line).

In the present experiment, we used an $\mathrm{Si}(111)$ crystal glued to a cylindrically shaped support. The crystal consists of 100 segments, each $1 \times 50 \mathrm{~mm}$ (focusing $\times$ dispersion) size, and a radius of curvature of the support of $250 \mathrm{~mm}$. The diffracted X-rays were measured by means of either a two-dimensional Pilatus $100 \mathrm{~K}$ detector [29,30] consisting of $195 \times 490$ pixels with $172 \times 172 \mu \mathrm{m}^{2}$ size, or a Mythen strip detector consisting of a linear array of 1280 pixels of dimension $50 \mu \mathrm{m} \times 8 \mathrm{~mm}[31,32]$. Both detectors are photon-counting, so all reported signals are directly in counted photons. To measure the IXS signals, the spectrometer was operated at a Bragg angle (marked as $\Theta_{B}$ in Figure 1b) of around 80 degrees and $\mathrm{Si}(444)$ diffraction, and arranged in the backscattering geometry. Using such a setup, the spectrometer could record X-rays of energy around $8030 \mathrm{eV}$ and a dispersive energy bandwidth of $80 \mathrm{eV}$. The incident $\mathrm{X}$-ray beam was delivered by an $\mathrm{Si}(311)$ monochromator and focused down to a size of $100 \times 100 \mu \mathrm{m}^{2}$ onto the sample position by means of a Pt-coated mirror. The higher energy $X$-rays were rejected by primary Si mirror operated at an angle of 3 mrad. The experimental resolution, measured from the full-width at half maximum (FWHM) of elastically scattered photons from a piece of solid $\mathrm{Pb}$, was found to be $300 \mathrm{meV}$ (see Figure 2), indicating that the main broadening contribution is from the $\mathrm{Si}(311)$ monochromator bandwidth $(250 \mathrm{meV})$, while the influence from the spectrometer is substantially smaller. The experimental data were fitted with the convolution of two Gauss functions representing the contributions of experimental broadening from the incidence beam and spectrometer, respectively. In the fit, the FWHM of the incidence beam was fixed to $250 \mathrm{meV}$ and the width of the spectrometer contribution was left as a free parameter. From this procedure, the FWHM of the spectrometer contribution was found to be $164 \mathrm{meV}$, which includes all other contributions to the experimental energy resolution [5]. The primary reason for this improved spectrometer resolution, in comparison to previous results, is due to the decreased segment size from 5 to $1 \mathrm{~mm}$, which reduces the geometric contribution to the energy resolution [5]. 


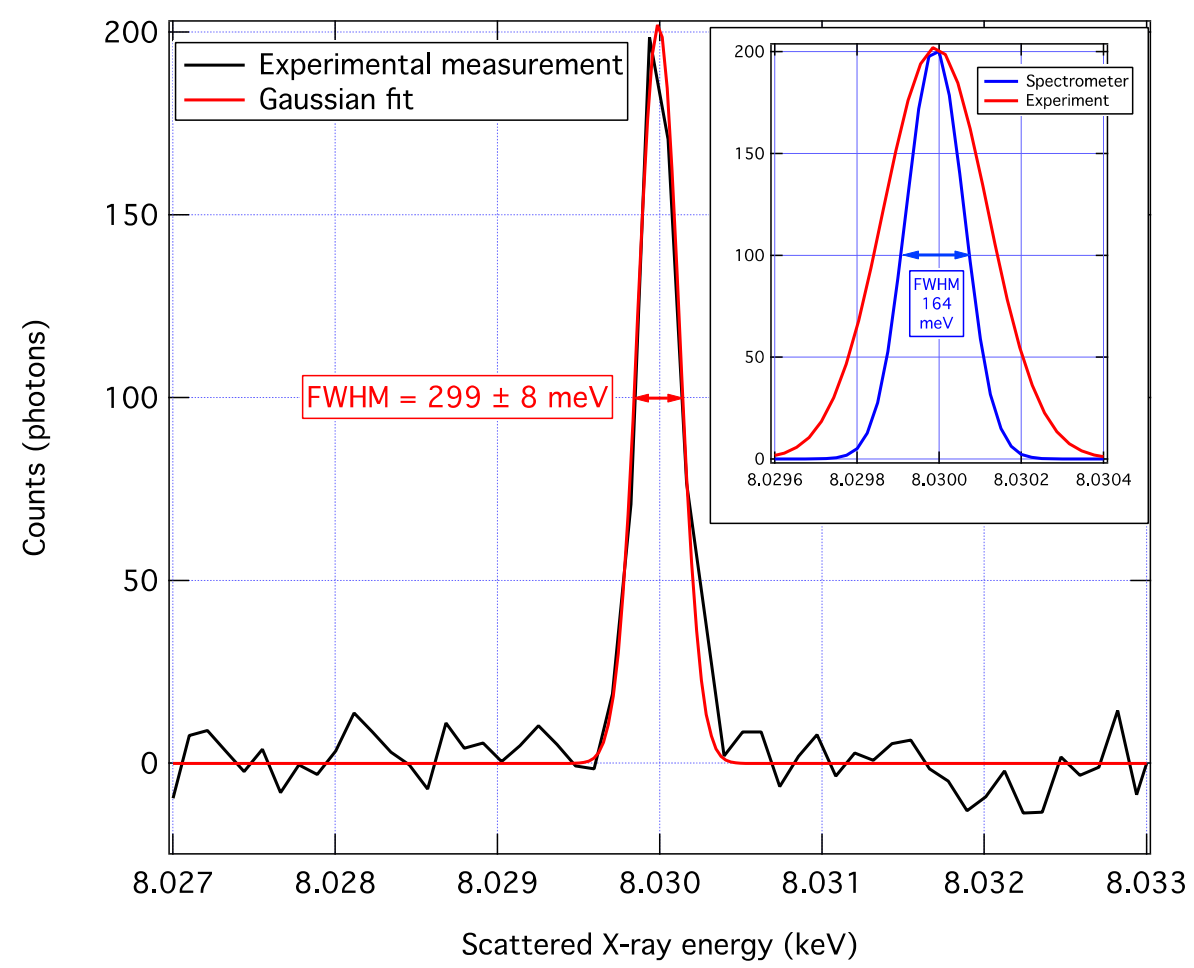

Figure 2. Elastically scattered X-rays measured using the von Hamos spectrometer with the $\mathrm{Si}(444)$ diffraction signal at a Bragg angle of around 80 degrees and an X-ray energy of $8030 \mathrm{eV}$. The incident beam was monochromatized using an $\mathrm{Si}(311)$ channel-cut monochromator, resulting in a $250 \mathrm{meV}$ incident X-ray bandwidth. Inset: A Gaussian fit to the experimental measurement (red) overlaid with the de-convolved spectrometer energy resolution (blue).

\section{Results}

The IXS measurement of the C K-edge recorded from a chemical vapor deposition (CVD) diamond sample with the von Hamos spectrometer is plotted in Figure 3. The incident beam energy was set to $8350 \mathrm{eV}$. The spectrum is shifted in energy according to the energy conservation rule, in order to be compared with experimental data recorded by means of Electron Loss Near Edge Spectroscopy (ELNES) [33,34]. As shown, excellent agreement is obtained between the spectra. A total incident photon flux of around $10^{15}-10^{16}$ photons was needed to record a good quality IXS signal. Following the ELNES and XAS experimental and theoretical interpretation, the first peak at around $292 \mathrm{eV}$ corresponds to $1 \mathrm{~s} \rightarrow \sigma^{*}$ excitation, while the features from $295-310 \mathrm{eV}$ relate to $\sigma$-type unoccupied states, and the peak at $328 \mathrm{eV}$ is the first EXAFS feature. 


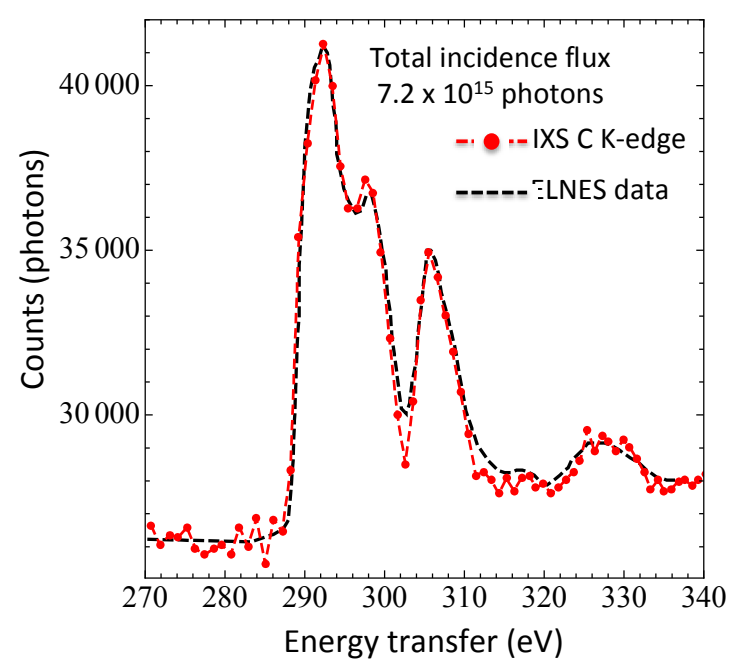

Figure 3. IXS signal of the carbon K-edge of a chemical vapor deposition (CVD) diamond sample. Electron Loss Near Edge Spectroscopy (ELNES) data adapted from Reference [33] with permission from the Royal Society of Chemistry.

The IXS technique has the capability to probe not only K-edges of low Z elements but also the absorption spectra of higher electronic levels. As an example, we performed the IXS measurements on Ti to detect the 3p and 3s absorption spectra by means of IXS. As sample, we used a 5- $\mu$ m-thick Ti foil. The spectrometer settings were the same as in the case of the IXS C K-edge measurements with the incident beam energy tuned to energy of $8070 \mathrm{eV}$. The resulting spectrum is plotted in Figure 4. Two distinct features are observed at an energy transfer range between 20 and $80 \mathrm{eV}$. The first feature located at $30-45 \mathrm{eV}$ corresponds to the $3 \mathrm{p}$ absorption spectrum. A sharp peak at $38 \mathrm{eV}$ is detected that corresponds to $3 \mathrm{p} \rightarrow \mathrm{d}$ excitation. The second feature at energies above $55 \mathrm{eV}$ relates to 3 s absorption. Resonance excitation is observed at $60 \mathrm{eV}$, that corresponds to dipole $3 \mathrm{~s} \rightarrow \mathrm{p}$ transition. Note that these transitions probe the same final electronic states as Ti K- and L-edge spectroscopies, and are difficult to address without using electron spectroscopic techniques.

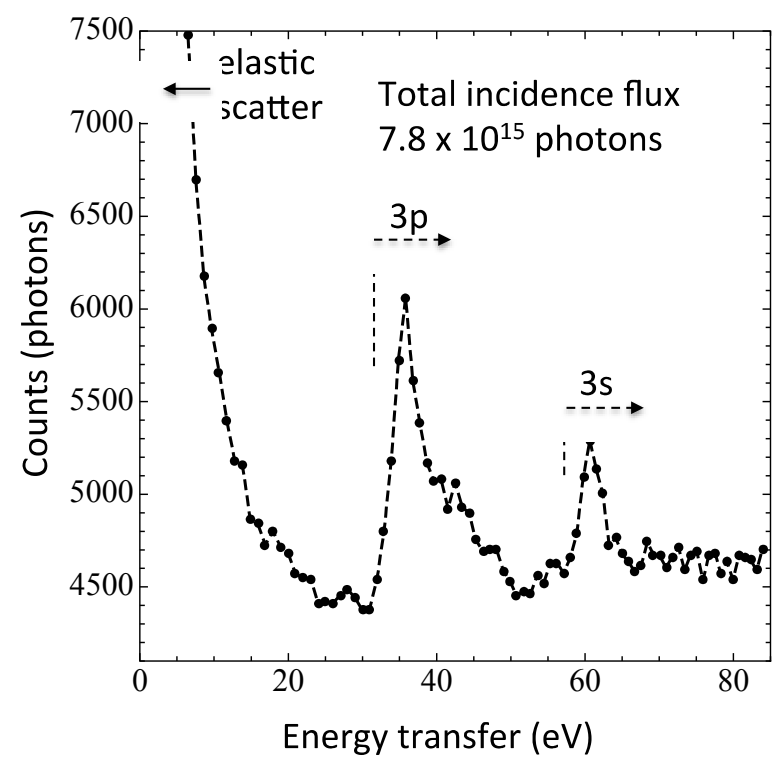

Figure 4. IXS signal of Ti foil showing the excitation signatures of $3 p \rightarrow d$ and $3 s \rightarrow p$. 
One of the significant advantages of the IXS technique is the ability to probe bulk samples, such as liquid water. The oxygen IXS signals from water are shown in Figure 5. The O K-edge measurement (Figure 5 right) shows the characteristic XAS and EXAFS of liquid water [35-37], with no contribution from the gas-phase species [38], as expected for a bulk measurement. As for the Ti sample, the dispersive spectrometer can also easily access higher-lying excitations, in this case excitations from the $1 b_{2}$ and $2 a_{1}$ molecular orbitals of the water molecule [39]. In general, these types of excitations are measured using photoemission, which requires vacuum techniques to be applied [40]. Here, we measure the signals from the bulk liquid under ambient atmospheric conditions.
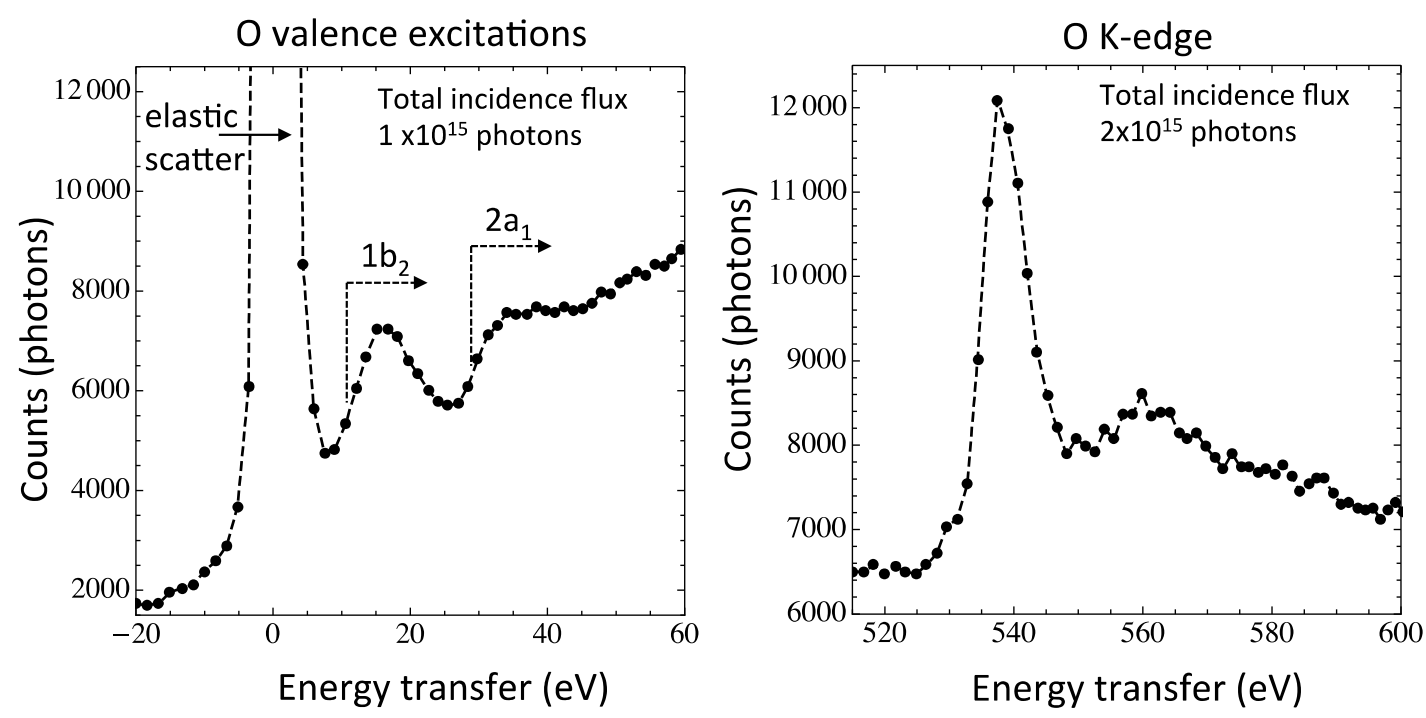

Figure 5. IXS signal of liquid water. Left: high-lying excitations from the molecular orbitals of the water molecule sitting on top of the Compton scattering signal. Right: The O K-edge IXS signal, showing the characteristics of bulk water.

\section{Discussion}

The presented spectrometer design has been shown to be ideal for a range of different types of $X$-ray experiments including both off- and on-resonant $X$-ray techniques $[5,8,41-44]$. Here, we have demonstrated its application to inelastic X-ray scattering to probe low-energy electronic excitations in condensed matter. Due to its unique combination of large solid angle and high-energy resolution, it can measure IXS signals within realistic timescales of several hours at a bending magnet beamline (X-ray flux $10^{11}$ photons/second $/ 0.015 \%$ bandwidth) at a third-generation storage ring X-ray source. Increasing the number of crystals used is a straightforward way of increasing the $\mathrm{X}$-ray signals.

In terms of the application of a short working distance von Hamos spectrometer to IXS measurements at XFEL sources, the required incident photon flux for the measured IXS signals as shown in Figures $3-5$ are in the range of $10^{15}-10^{16}$ photons. Assuming an XFEL pulse intensity of $10^{11}$ photons and $100 \mathrm{~Hz}$ operation would translate to about $1000 \mathrm{~s}$ of total acquisition time. Therefore, a large margin is left for improved spectra quality by increasing the acquisition time to several hours. For example at a total of $2 \times 10^{15}$ incident photons for the liquid water sample, we note the statistical error for the maximum white line intensity to be around $1.4 \%$, which can be further diminished to $0.14 \%$ for $24 \mathrm{~h}$ acquisition at an XFEL. Such a level of uncertainty is sufficient for many pump-probe experiments where signal differences on the level of a few percent are detected by means of X-ray absorption and X-ray emission spectroscopies [45]. We would like to emphasize that the present studies include only one analyzer crystal; thus, further signal enhancement may be achieved by application of multi-crystal arrangements, as commonly applied for X-ray emission spectroscopy setups [46]. We anticipate that IXS can be used to probe ultrafast structural and electronic dynamics in samples such 
as graphite [47] and liquid water [48-50], with a possible extension to probing more dilute species at higher repetition rate XFEL sources in the future [51].

Acknowledgments: The authors would like to acknowledge the contributions of Jörg Schneider and Konrad Vogelsang to the manufacture and assembly of the segmented crystals. Furthermore, we would like to acknowledge the contributions of Beat Meyer, Urs Vogelsang, and Lorenz Baeni for their technical support during the measurements.

Author Contributions: Jakub Szlachetko and Christopher J. Milne conceived and designed the experiments; Jakub Szlachetko, Christopher J. Milne, Joanna Czapla-Masztafiak, Sergey Peredkov, Gregor Knopp, Maarten Nachtegaal, and Daniel Grolimund performed the experiments; Jakub Szlachetko and Christopher J. Milne. analyzed the data; Jakub Szlachetko and Christopher J. Milne wrote the paper with contributions from all authors.

Conflicts of Interest: The authors declare no conflict of interest.

\section{References}

1. Bergmann, U.; Glatzel, P. X-ray emission spectroscopy. Photosynth. Res. 2009, 102, 255-266. [CrossRef] [PubMed]

2. Glatzel, P.; Bergmann, U. High resolution 1s core hole X-ray spectroscopy in 3d transition metal complexes-Electronic and structural information. Coord. Chem. Rev. 2005, 249, 65-95. [CrossRef]

3. Huotari, S.; Sahle, C.J.; Henriquet, C.; Al-Zein, A.; Martel, K.; Simonelli, L.; Verbeni, R.; Gonzalez, H.; Lagier, M.C.; Ponchut, C.; et al. A large-solid-angle X-ray Raman scattering spectrometer at ID20 of the European Synchrotron Radiation Facility. J. Synchrotron Rad. 2017, 24, 521-530. [CrossRef] [PubMed]

4. Tohji, K.; Udagawa, Y. X-ray Raman scattering as a substitute for soft-X-ray extended X-ray-absorption fine structure. Phys. Rev. B 1989, 39, 7590-7594. [CrossRef]

5. Szlachetko, J.; Nachtegaal, M.; de Boni, E.; Willimann, M.; Safonova, O.; Sa, J.; Smolentsev, G.; Szlachetko, M.; van Bokhoven, J.A.; Dousse, J.C.; et al. A von Hamos X-ray spectrometer based on a segmented-type diffraction crystal for single-shot $X$-ray emission spectroscopy and time-resolved resonant inelastic $\mathrm{X}$-ray scattering studies. Rev. Sci. Instrum. 2012, 83, 103105. [CrossRef] [PubMed]

6. Milne, C.J.; Szlachetko, J.; Penfold, T.; Santomauro, F.; Britz, A.; Gawelda, W.; Doumy, G.; March, A.M.; Southworth, S.H.; Rittmann, J.; et al. Time-resolved X-ray absorption and emission spectroscopy on ZnO nanoparticles in solution. In Optical Society of America: Okinawa; OSA Publishing: Washington, DC, USA, 2014.

7. Penfold, T.J.; Szlachetko, J.; Gawelda, W.; Santomauro, F.G.; Britz, A.; van Driel, T.B.; Sala, L.; Ebner, S.; Southworth, S.H.; Doumy, G.; et al. Femtosecond X-ray Absorption and Emission Spectroscopy on ZnO Nanoparticles in Solution. In Proceedings of the Optical Society of America, Santa Fe, NM, USA, 17-22 July 2016.

8. Szlachetko, J.; Milne, C.J.; Hoszowska, J.; Dousse, J.C.; Błachucki, W.; Sa, J.; Kayser, Y.; Messerschmidt, M.; Abela, R.; Boutet, S.; et al. Communication: The electronic structure of matter probed with a single femtosecond hard X-ray pulse. Struct. Dyn. 2014, 1, 021101. [CrossRef] [PubMed]

9. Szlachetko, J.; Hoszowska, J.; Dousse, J.-C.; Nachtegaal, M.; Błachucki, W.; Kayser, Y.; Sa, J.; Messerschmidt, M.; Boutet, S.; Williams, G.J.; et al. Establishing nonlinearity thresholds with ultraintense X-ray pulses. Sci. Rep. 2016, 6, 33292. [CrossRef] [PubMed]

10. March, A.M.; Stickrath, A.; Doumy, G.; Kanter, E.P.; Krässig, B.; Southworth, S.H.; Attenkofer, K.; Kurtz, C.A.; Chen, L.X.; Young, L. Development of high-repetition-rate laser pump/X-ray probe methodologies for synchrotron facilities. Rev. Sci. Instrum. 2011, 82, 073110. [CrossRef] [PubMed]

11. Ishikawa, T.; Aoyagi, H.; Asaka, T.; Asano, Y.; Azumi, N.; Bizen, T.; Ego, H.; Fukami, K.; Fukui, T.; Furukawa, Y.; et al. A compact X-ray free-electron laser emitting in the sub-ångström region. Nat. Photonics 2012, 6, 540-544. [CrossRef]

12. Emma, P.J.; Akre, R.; Arthur, J.; Bionta, R.; Bostedt, C.; Bozek, J.; Brachmann, A.; Bucksbaum, P.; Coffee, R.; Decker, F.J.; et al. First lasing and operation of an ångstrom-wavelength free-electron laser. Nat. Photonics 2010, 4, 641-647. [CrossRef]

13. Milne, C.J.; Beaud, P.; Deng, Y.; Erny, C.; Follath, R.; Flechsig, U.; Hauri, C.P.; Ingold, G.; Juranić, P.; Knopp, G.; et al. Opportunities for Chemistry at the SwissFEL X-ray Free Electron Laser. CHIMIA 2017, 71, 299-307. [CrossRef] [PubMed] 
14. Milne, C.J.; Schietinger, T.; Aiba, M.; Alarcon, A.; Alex, J.; Anghel, A.; Arsov, V.; Beard, C.; Beaud, P.; Bettoni, S.; et al. SwissFEL: The Swiss X-ray Free Electron Laser. Appl. Sci. 2017, 7, 720. [CrossRef]

15. Mizuno, Y.; Ohmura, Y. Theory of X-Ray Raman Scattering. J. Phys. Soc. Jpn. 1967, 22, 445-449. [CrossRef]

16. Suzuki, T. X-Ray Raman Scattering Experiment. I. J. Phys. Soc. Jpn. 1967, 22, 1139-1150. [CrossRef]

17. Tohji, K.; Udagawa, Y. Observation of X-ray Raman scattering. Phys. B Condens. Matter 1989, 158, 550-552. [CrossRef]

18. Bergmann, U.; Glatzel, P.; Cramer, S.P. Bulk-sensitive XAS characterization of light elements: From X-ray Raman scattering to X-ray Raman spectroscopy. Microchem. J. 2002, 71, 221-230. [CrossRef]

19. Miedema, P.S.; Ngene, P.; van der Eerden, A.M.J.; Sokaras, D.; Weng, T.-C.; Nordlund, D.; Au, Y.S.; de Groot, F.M.F. Experimental section. Phys. Chem. Chem. Phys. 2014, 16, 22651-22658. [CrossRef] [PubMed]

20. Miedema, P.S.; Ngene, P.; van der Eerden, A.M.J.; Weng, T.-C.; Nordlund, D.; Sokaras, D.; Alonso-Mori, R.; Juhin, A.; de Jongh, P.E.; de Groot, F.M.F. In situ X-ray Raman spectroscopy of $\mathrm{LiBH}_{4}$. Phys. Chem. Chem. Phys. 2012, 14, 5581-5587. [CrossRef] [PubMed]

21. Bergmann, U.; Di Cicco, A.; Wernet, P.; Principi, E.; Glatzel, P.; Nilsson, A. Nearest-neighbor oxygen distances in liquid water and ice observed by X-ray Raman based extended X-ray absorption fine structure. J. Chem. Phys. 2007, 127. [CrossRef] [PubMed]

22. Bergmann, U.; Wernet, P.; Glatzel, P.; Cavalleri, M.; Pettersson, L.G.M.; Nilsson, A.; Cramer, S.P. X-ray raman spectroscopy at the oxygen K edge of water and ice: Implications on local structure models. Phys. Rev. B 2002, 66, 921071-921074. [CrossRef]

23. Verbeni, R.; Kocsis, M.; Huotari, S.; Krisch, M.; Monaco, G.; Sette, F.; Vankó, G. Advances in crystal analyzers for inelastic X-ray scattering. J. Phys. Chem. Solids 2005, 66, 2299-2305. [CrossRef]

24. Verbeni, R.; Pylkkaenen, T.; Huotari, S.; Simonelli, L.; Vankó, G.; Martel, K.; Henriquet, C.; Monaco, G. Multiple-element spectrometer for non-resonant inelastic X-ray spectroscopy of electronic excitations. J. Synchrotron Rad. 2009, 16, 469-476. [CrossRef] [PubMed]

25. Sokaras, D.; Nordlund, D.; Weng, T.C.; Mori, R.A.; Velikov, P.; Wenger, D.; Garachtchenko, A.; George, M.; Borzenets, V.; Johnson, B.; et al. A high resolution and large solid angle X-ray Raman spectroscopy end-station at the Stanford Synchrotron Radiation Lightsource. Rev. Sci. Instrum. 2012, 83, 043112. [CrossRef] [PubMed]

26. Amann, J.; Berg, W.; Blank, V.; Decker, F.J.; Ding, Y.; Emma, P.J.; Feng, Y.; Frisch, J.; Fritz, D.; Hastings, J.; et al. Demonstration of self-seeding in a hard-X-ray free-electron laser. Nat. Photonics 2012, 6, 693-698. [CrossRef]

27. Lemke, H.T.; Bressler, C.; Chen, L.X.; Fritz, D.M.; Gaffney, K.J.; Galler, A.; Gawelda, W.; Haldrup, K.; Hartsock, R.W.; Ihee, H.; et al. Femtosecond X-ray Absorption Spectroscopy at a Hard X-ray Free Electron Laser: Application to Spin Crossover Dynamics. J. Phys. Chem. A 2013, 117, 735-740. [CrossRef] [PubMed]

28. Ratner, D.; Abela, R.; Amann, J.; Behrens, C.; Bohler, D.; Bouchard, G.; Bostedt, C.; Boyes, M.; Chow, K.; Cocco, D.; et al. Experimental demonstration of a soft X-ray self-seeded free-electron laser. Phys. Rev. Lett. 2015, 114. [CrossRef] [PubMed]

29. Broennimann, C.; Eikenberry, E.F.; Henrich, B.; Horisberger, R.; Huelsen, G.; Pohl, E.; Schmitt, B.; Schulze-Briese, C.; Suzuki, M.; Tomizaki, T.; et al. The PILATUS 1M detector. J. Synchrotron Rad. 2006, 13, 120-130. [CrossRef] [PubMed]

30. Henrich, B.; Bergamaschi, A.; Broennimann, C.; Dinapoli, R.; Eikenberry, E.F.; Johnson, I.; Kobas, M.; Kraft, P.; Mozzanica, A.; Schmitt, B. PILATUS: A single photon counting pixel detector for X-ray applications. Nucl. Inst. Methods Phys. Res. Sect. A 2009, 607, 247-249. [CrossRef]

31. Bergamaschi, A.; Cervellino, A.; Dinapoli, R.; Gozzo, F.; Henrich, B.; Johnson, I.; Kraft, P.; Mozzanica, A.; Schmitt, B.; Shi, X. The MYTHEN detector for X-ray powder diffraction experiments at the Swiss Light Source. J. Synchrotron Rad. 2010, 17, 653-668. [CrossRef] [PubMed]

32. Schmitt, B.; Brönnimann, C.; Eikenberry, E.F.; Gozzo, F.; Hörmann, C.; Horisberger, R.; Patterson, B. Mythen detector system. Nucl. Instrum. Method A 2003, 501, 267-272. [CrossRef]

33. Hamon, A.-L.; Verbeeck, J.; Schryvers, D.; Benedikt, J.; vd Sanden, R.M. ELNES study of carbon K-edge spectra of plasma deposited carbon films. J. Mater. Chem. 2004, 14, 2030. [CrossRef]

34. Merchant, A.R.; McCulloch, D.G.; Brydson, R. A comparison of experimental and calculated electron-energy loss near-edge structure of carbon, and the nitrides of boron, carbon and silicon using multiple scattering theory. Diam. Relat. Mater. 1998, 7, 1303-1307. [CrossRef] 
35. Näslund, L.Å.; Luning, J.; Ufuktepe, Y.; Ogasawara, H.; Wernet, P.; Bergmann, U.; Pettersson, L.G.M.; Nilsson, A. X-ray Absorption Spectroscopy Measurements of Liquid Water. J. Phys. Chem. B 2005, 109, 13835-13839. [CrossRef] [PubMed]

36. Yang, B.; Kirz, J. Extended X-ray-absorption fine structure of liquid water. Phys. Rev. B 1987, 36, $1361-1364$. [CrossRef]

37. Fukui, H.; Huotari, S.; Andrault, D.; Kawamoto, T. Oxygen K-edge fine structures of water by X-ray Raman scattering spectroscopy under pressure conditions. J. Chem. Phys. 2007, 127, 134502-134504. [CrossRef] [PubMed]

38. Myneni, S.; Luo, Y.; Näslund, L.Å.; Cavalleri, M.; Ojamae, L.; Ogasawara, H.; Pelmenschikov, A.; Wernet, P.; Väterlein, P.; Heske, C.; et al. Spectroscopic probing of local hydrogen-bonding structures in liquid water. J. Phys.-Condens Matter 2002, 14, L213-L219. [CrossRef]

39. Winter, B.; Weber, R.; Widdra, W.; Dittmar, M.; Faubel, M.; Hertel, I.V. Full Valence Band Photoemission from Liquid Water Using EUV Synchrotron Radiation. J. Phys. Chem. A 2004, 108, 2625-2632. [CrossRef]

40. Winter, B.; Faubel, M. Photoemission from liquid aqueous solutions. Chem. Rev. 2006, 106, 1176-1211. [CrossRef] [PubMed]

41. Szlachetko, J.; Nachtegaal, M.; Sa, J.; Dousse, J.-C.; Hoszowska, J.; Kleymenov, E.; Janousch, M.; Safonova, O.V.; König, C.; van Bokhoven, J.A. High energy resolution off-resonant spectroscopy at sub-second time resolution: (Pt(acac)2) decomposition. Chem. Commun. 2012, 48, 10898. [CrossRef] [PubMed]

42. Szlachetko, J.; Sa, J.; Safonova, O.V.; Smolentsev, G.; Szlachetko, M.; van Bokhoven, J.A.; Nachtegaal, M. In situ hard X-ray quick rixs to probe dynamic changes in the electronic structure of functional materials. J. Electron. Spectrosc. 2013, 188, 161-165. [CrossRef]

43. Szlachetko, J.; Ferri, D.; Marchionni, V.; Kambolis, A.; Safonova, O.V.; Milne, C.J.; Kröcher, O.; Nachtegaal, M.; $\mathrm{Sa}$, J. Subsecond and in Situ Chemical Speciation of $\mathrm{Pt} / \mathrm{Al}_{2} \mathrm{O}_{3}$ during Oxidation-Reduction Cycles Monitored by High-Energy Resolution Off-Resonant X-ray Spectroscopy. J. Am. Chem. Soc. 2013, 135, 19071-19074. [CrossRef] [PubMed]

44. Błachucki, W.; Szlachetko, J.; Hoszowska, J.; Dousse, J.C.; Kayser, Y.; Nachtegaal, M.; Sa, J. High Energy Resolution Off-Resonant Spectroscopy for X-Ray Absorption Spectra Free of Self-Absorption Effects. Phys. Rev. Lett. 2014, 112, 173003. [CrossRef] [PubMed]

45. Milne, C.J.; Penfold, T.J.; Chergui, M. Recent experimental and theoretical developments in time-resolved X-ray spectroscopies. Coord. Chem. Rev. 2014, 277, 44-68. [CrossRef]

46. Alonso-Mori, R.; Kern, J.; Sokaras, D.; Weng, T.-C.; Nordlund, D.; Tran, R.; Montanez, P.; Delor, J.; Yachandra, V.K.; Yano, J.; et al. A multi-crystal wavelength dispersive X-ray spectrometer. Rev. Sci. Instrum. 2012, 83, 073114. [CrossRef] [PubMed]

47. Van der Veen, R.M.; Penfold, T.J.; Zewail, A.H. Ultrafast core-loss spectroscopy in four-dimensional electron microscopy. Struct. Dyn. 2015, 2, 24302-24313. [CrossRef] [PubMed]

48. Wen, H.; Huse, N.; Schoenlein, R.W.; Lindenberg, A.M. Ultrafast conversions between hydrogen bonded structures in liquid water observed by femtosecond X-ray spectroscopy. J. Chem. Phys. 2009, 131, 234505. [CrossRef] [PubMed]

49. Huse, N.; Wen, H.; Nordlund, D.; Szilagyi, E.; Daranciang, D.; Miller, T.A.; Nilsson, A.; Schoenlein, R.W.; Lindenberg, A.M. Probing the hydrogen-bond network of water via time-resolved soft X-ray spectroscopy. Phys. Chem. Chem. Phys. 2009, 11, 3951-3957. [CrossRef] [PubMed]

50. Wernet, P.; Gavrila, G.; Godehusen, K.; Weniger, C.; Nibbering, E.T.J.; Elsaesser, T.; Eberhardt, W. Ultrafast temperature jump in liquid water studied by a novel infrared pump-X-ray probe technique. Appl. Phys. A 2008, 92, 511-516. [CrossRef]

51. Tschentscher, T.; Bressler, C.; Grünert, J.; Madsen, A.; Mancuso, A.; Meyer, M.; Scherz, A.; Sinn, H.; Zastrau, U. Photon Beam Transport and Scientific Instruments at the European XFEL. Appl. Sci. 2017, 7, 592. [CrossRef]

(C) 2017 by the authors. Licensee MDPI, Basel, Switzerland. This article is an open access article distributed under the terms and conditions of the Creative Commons Attribution (CC BY) license (http:/ / creativecommons.org/licenses/by/4.0/). 